\title{
Ontogenetic changes in leaf development and photosyn- thesis of Prunus serotina seedlings
}

\author{
S.B. Horsley ${ }^{1}$ and K.W. Gottschalk ${ }^{2}$ \\ 1 Northeastern Forest Experiment Station, USDA-Forest Service, P.O. Box 928, Warren, PA \\ 16365 , and \\ 2 P.O. Box 4360, Morgantown, WV 26505, U.S.A.
}

\section{Introduction}

Black cherry (Prunus serotina Ehrh.) is an important commercial hardwood species in the northeastern United States. The species is considered intolerant of overstory shade, although young seedlings usually develop in the shade of an overstory or in partially cut stands. Leaf age and developmental stage are important determinants of many physiological processes in trees, especially those with indeterminate growth. Net photosynthetic rate is a process that influences survival or death of young seedlings. Relationships between plant age, leaf age and development, and net photosynthesis have been investigated for only a few hardwood species.

\section{Materials and Methods}

Black cherry plants were raised from half-sib seed and grown in sand culture watered daily with a complete mineral nutrient solution. The plants were grown in growth chambers at $25^{\circ} \mathrm{C}$ during $16 \mathrm{~h}$ d under approximately $335 \mu \mathrm{mol}$ $\mathrm{m}^{-2} \cdot \mathrm{s}^{-1}$ PPFD from cool white fluorescent and incandescent lamps. Nights were $8 \mathrm{~h}$ at $18^{\circ} \mathrm{C}$. Humidity was not regulated. We removed the cotyledons and first 4 leaves when plants reached the 8-10 leaf stage, since these leaves often abscised. So the 5th true leaf produced was given the serial leat number 1 . We used the plastochron index of Erickson and Michelini (1957) to measure age of plants, and of leaves on plants in units of developmental time. The index leaf length was set at $75 \mathrm{~mm}$, since smaller leaves were difficult to handle in our leaf chambers due to their short petioles. The plastochron index was calculated from measurements of the smallest leaf that had a leaf lamina at least $75 \mathrm{~mm}$ long and the next serial numbered leaf above it.

Leaf area was measured on 277 leaves from 14 plants ranging in plastochron age from 18-40. Each leaf was measured in situ 3 times with a Li-Cor leal area meter. The length and width of each leaf were measured to the nearest $\mathrm{mm}$ with a ruler. The average area from the 3 measurements was used to develop predictive models for leaf area. Net photosynthesis was measured in a $20 \mathrm{~cm}$ water-cooled, plexiglass leaf chamber by infrared gas analysis in an open system. The system was operated with $330 \mathrm{ppm}$ of humidified $\mathrm{CO}_{2}$ at a leaf temperature of $25 \pm 0.5^{\circ} \mathrm{C}$. Illumination was provided with a single $400 \mathrm{~W}$ sodium iodide metal arc lamp at $600 \mu \mathrm{mol} \mathrm{m}-2 \cdot \mathrm{s}^{-1}$ PPFD. Gas flow was maintained at $900 \mathrm{ml} / \mathrm{min}$. Prior to insertion in the leaf chamber, leaf area was measured with a Li-Cor leaf area meter. We measured plants ranging in age from 7 to 20 plastochrons. 
Vertical profiles were measured on 3-5 plants at each plant age on all leaves $75 \mathrm{~mm}$ and longer, beginning with serial leaf number 7 . For example, only leaf 7 was measured on a plastochron age 7 plant, whereas leaves 7 through 20 were measured on a plastochron age 20 plant (Dickmann, 1971).

\section{Results}

All of the models tested to predict leaf area from various combinations of leaf length and width had good correlations and significant regressions. Several models explained $97 \%$ or more of the variation. The simplest of these models is the linear regression which explained $98 \%$ of the variation and does a good job of predicting leaf area from length and width measurements.

Under our growing conditions, the plastochron interval, or length of chronological time between the time a leaf reaches index leaf length of $75 \mathrm{~mm}$ and the time the next serial numbered leaf above it reaches $75 \mathrm{~mm}$, varied from 1 to $3 \mathrm{~d}$ on different plants. Leaves with serial leaf numbers less than about 9 were shorter, had less leaf area and often had a larger plastochron interval than higher serial numbered leaves. Leaves on older plants required a greater number of plastochrons to reach full expansion than leaves on younger plants. Maximum leaf size became stable between serial leaf numbers 10 and 13. Leaves on older plants also required successively more plastochrons to reach maximum net photosynthesis. Leaf area increased with leaf plastochron age (LPA) up to a maximum at LPA 4-5 and then remained constant. As plant size increased, mean leaf area increased from 47.2 to 57.5 to $62.2 \mathrm{~cm}^{2}$ for 7,10 and 13 leaf plants, respectively.

Since our index leaf was comparatively long, all of the leaves we measured were net producers of photosynthetic products. Maximum net photosynthesis was reached before leaves were fully expanded. In a horizontal series, serial leaf number 7 , maximum net photosynthesis was reached at $L P A 2$, while full expansion of leaves was not reached until $L P A$ 4-5. Maximum net photosynthesis was maintained for only a few plastochrons in leaf 7 before it began to decline gradually. Average net photosynthetic rate was higher in leaves of the same LPA on younger plants than on older plants. In an oblique series, average $P n$ of $L P A 3$ leaves was $0.270,0.227$, and $0.176 \mathrm{mg} \mathrm{CO} \cdot \mathrm{m}^{-2-1}$ in plants with 10,15 and 20 leaves, respectively. In a vertical series, net photosynthesis increases to a maximum at $L P A 2-3$ in younger plants and $3-4$ in older plants, maintains that rate for several plastochrons, and then declines gradually. Maximum net photosynthesis is maintained for a shorter time in leaves on younger plants than in leaves on older plants, ranging from 4 to 9 plastochrons. Older plants have many leaves producing at the maximum net photosynthetic rate, but at a lower rate than in younger plants. A large proportion of the leaves on $L P A 7-20$ plants have net photosynthetic rates within $90 \%$ of the maximum rate for that aged plant.

\section{Discussion and Conclusion}

Developmental patterns of black cherry leaves are very similar to those of other indeterminate growth hardwoods, such as the poplars (Larson and Isebrands, 1971). Leaves grow in a predictable and constant fashion under constant growth chamber conditions. The light condition used in the growth chambers was low, however, it was still higher than the light level in the understory of black cherry stands where 
seedlings compete with other plants for survival. The photosynthetic rates reported are shade leaf values rather than sun leaf due to this low light condition.

Photosynthetic rates of other Prunus species all showed rates and developmental patterns similar to those of black cherry for both growth chamber and field measurements (Andersen and Brodbeck, 1988; Crews et al., 1975; Sams and Flore, 1983; Even-Chen et al., 1981). The only exception was field-grown sour cherry seedlings that had rates double those of all other reports (Sams and Flore, 1982). The photosynthetic and leaf developmental patterns of black cherry seedlings are tools that can now be used as measures of response to treatments. Problems in regenerating black cherry due to interference from herbaceous and woody plants are very serious problems in millions of acres of forest. Studies on mechanisms of interference and amelioration of interference that are being conducted will use these techniques.

\section{References}

Andersen P.C. \& Brodbeck B.V. (1988) Water relations and net $\mathrm{CO}_{2}$ assimilation of peach leaves of different ages. J. Am. Soc. Hortic. Sci. 113, 242-248

Crews C.E., Williams S.L. \& Vines H.M. (1975) Characteristics of photosynthesis in peach leaves. Planta 42', 285-294

Dickmann D.I. (1971) Photosynthesis and respiration by developing leaves of cottonwood ( $P$ Opulus deltoides Bartr.). Bot. Gaz. 132, 253-259

Erickson R.O. \& Michelini F.J. (1957) The plastochron index. Arn. J. Bot. 44, 297-305

Even-Chen Z., Weinbaum S.A. \& Pearcy R.W. (1981) High temperature effects on leaf resistance, leaf water potential, and photosynthesis of non-bearing prune trees. J. Am. Soc. Hortic. Sci. 106, 216-219

Larson P.R. \& Isebrands J.G. (1971) The plastochron index as applied to developmental studies of cottonwood. Can. J. For. Res. 1, 1-11

Sams C.E. \& Flore J.A. (1982) The influence of age, position, and environmental variables on net photosynthetic rate of sour cherry leaves. J. Am. Soc. Hortic. Sci. 107, 339-344

Sams C.E. \& Flore J.A. (1983) Net photosynthetic rate of sour cherry (Prunus cerasus L. "Montmorency') during the growing season with reference to fruiting. Photosynth. Res. 4, 307-316 